\title{
Community structure, social organization and ecological requirements of coral reef fish (Pomacentridae)"
}

\author{
H. W. FRICKE \\ Max-Planck-Institut für Verbaltensphysiologie; Seeriesen, \\ Federal Republic of Germany
}

\begin{abstract}
In the Gulf of Aqaba (Red Sea), 25 species of damselfish (Pomacentridae) which form typical interspecific communities were studied. Several species are typical for different depth zones, others are "ubiquitous". Damselfish are variously specialized in feeding (herbivore, omnivore, plankton-carnivore); habitat (bottom-dwelling, midwater); home-and-shelter site (selective or unselective). Environmental factors and social structures were found to be interlinked. Species with the same social structure are similarly specialized ecologically. A hypothetical flow diagram shows the effects of abiotic and biotic factors on group size, available food, and social structure. Damselfish are extremely flexible to environmental change, showing intraspecific modification of group structure, feeding habits, reproductive strategy etc. Experimental results suggest a strong selection against "redundant" males. This research is considered a pilot study for future field work, aimed at a prediction of environmental influences on behaviour.
\end{abstract}

\section{INTRODUCTION}

Biologists are becoming aware that ecosystems are the most complicated biological systems they have to deal with. They are confronted with the difficult task of defining their working level, whether this is the tropic structure of a food chain, communities containing different species, various populations of the same species, or individuals or groups. All are intercausally connected and form what is commonly called the „ecosystem".

Each single organism displays a variety of activities - to gain energy - or to escape consumption by members of higher trophic levels. Energy intake is the goal of hunting or foraging techniques, while camouflage, escape, anti-predator aggression or anti-predation are self-preserving patterns which expend energy. Reproduction is another form of energy output; mates must find and select each other. Even solitary animals must seek a mate, and in directing their behaviour towards a conspecific they, at least temporarily, become social. Several forms of association exist which ensure

\footnotetext{
* Supported by the Deutsche Forschungsgemeinschaft, Bad Godesberg, and the Max-PlanckInstitut für Verhaltensphysiologie, Seewiesen.
} 
successfull reproduction between males and females. Monogamy, polygyny, polyandry an promiscuity are some of the mating patterns composing the social life of organism.

In each species, certain strategies for reproduction, energy acquisition and predator evasion have evolved. Inefficient strategies are counter-selected. Adaptive strategies of groups or individuals, therefore, are an integral part of the ecosystem.

I must emphasize that we cannot comprehend the functioning of an ecosystem merely by exploring the trophic structure of communities; the behavioural responses of groups and individuals must also be studied. This is an extremely difficult task.

I want to present a pilot study on a community of damselfish of the family Pomacentridae. First we will examine the structure of the pomacentrid community in the Gulf of Aqaba (Red Sea) and the social organization of the various species. Then we will concentrate on one species and its immediate behavioural responses to environmental changes, to determine the control exercised on behaviour by the environment.

Table 1

List of species studied and size of the smallest and biggest individuals caught

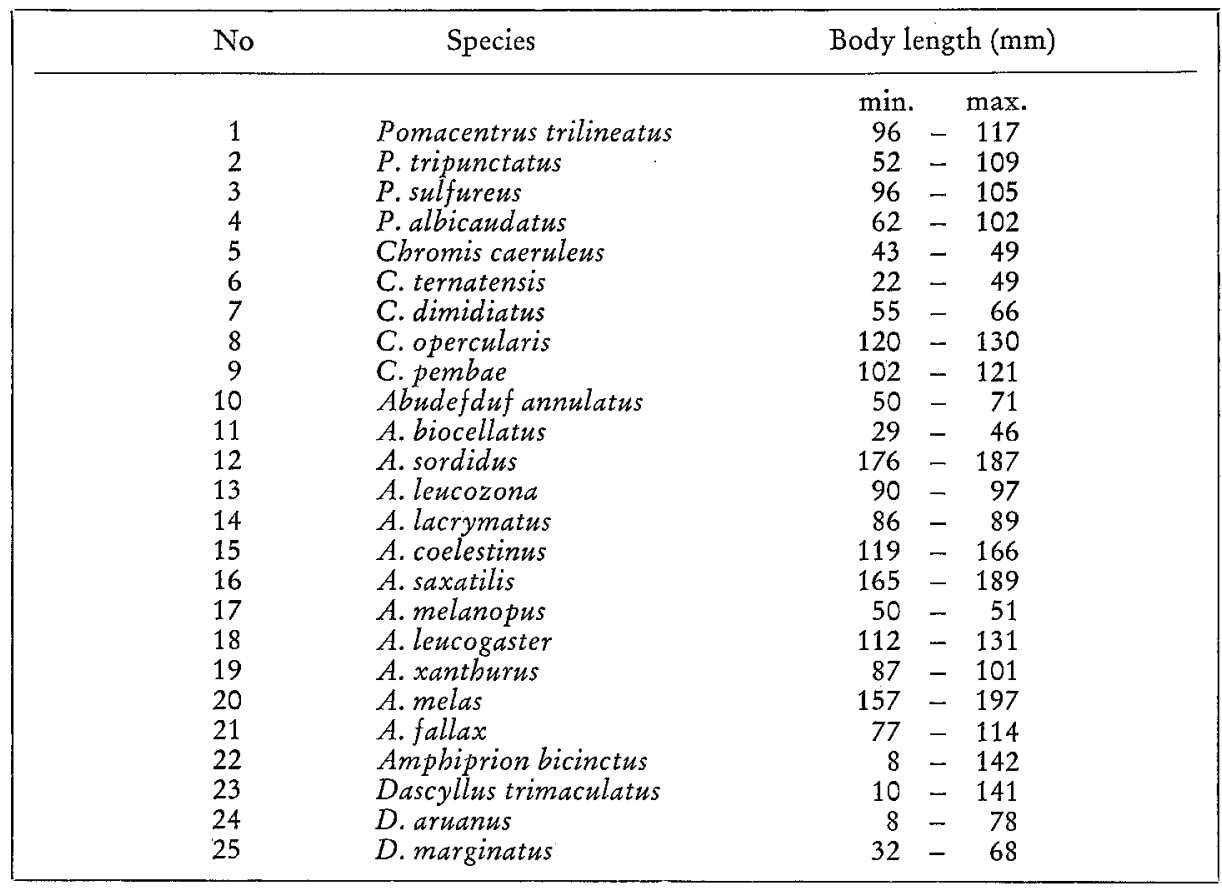

An evolutionary biologist, considering a species, would ask: what is its total range of behavioural modification in its present environment on the basis of its phylogenetic heritage? An ecologist asks: how do individuals or groups survive and coexist under the present conditions?

Pomacentrids are the most common fishes in tropical and subtropical seas. Their behaviour and ecology have been intensively investigated by Allen, Emery, Fishelson, 
Myrberg, Randall, Reese, Sale, Stevenson, Vine and others. The pertinent literature has been summarized and listed by Myrberg (1972) and Myrberg \& Tresher (1974).

In the Gulf of Aqaba we found 25 species (Table 1) of the genera Abudefduf. Amphiprion, Chromis, Dascyllus and Pomacentrus. I would like to summarize the results of some of our studies on the interrelationship of behaviour and ecology in these species, omitting methodological details and original data, both have been published in part elsewhere (Fricke, 1973, 1974, 1975a, 1975b).

\section{THE POPULATION STRUCTURE OF POMACENTRIDS IN THE GULF OF AQABA}

Fishelson (1974) presented a qualitative description of pomacentrid distribution in the Gulf of Aqaba; our aim was a more quantitative analysis of the population structure. Transects were laid at right angles to the coast at 106 stations along the eastern coast of the Sinai peninsula. Five different reef typek were recognized, corresponding with reef structures described by Mergner \& Schuhmacher (1974). The species

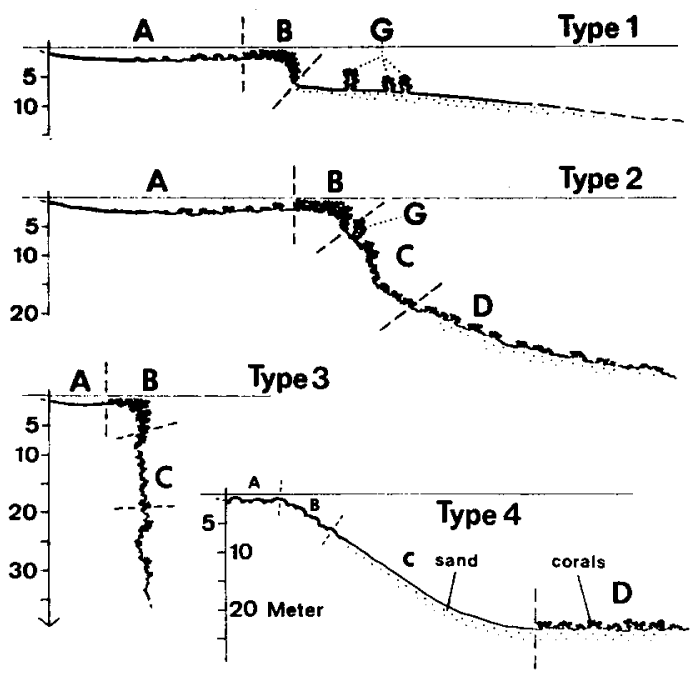

Fig. 1: Schematic representation of reef types in the Gulf of Aqaba with depth distribution of arbitrarily selected reef zones. A: 0-1 m, B: 1-7 m, C: 7-20 m, D: $>20 \mathrm{~m}$. Coral knolls (G) are considered as a special reef type (5)

distribution was measured in reef zones $(A, B, C, D)$ of varying depth $(A=0-1 \mathrm{~m}$, $B=1-7 \mathrm{~m}, C=7-20 \mathrm{~m}$ and $\mathrm{D}=>20 \mathrm{~m}$, Fig. 1$)$. The zones were depth distributed and, therefore, independent of the reef type. A six-grade relative density index, from 0 to 5 , was constructed. Figure 2 shows the frequency of species independent of density in different zones and for different reef types; we can see that pomacentrids occur in almost every reef type and zone. They were absent on sandy bottoms (reef type 4, 


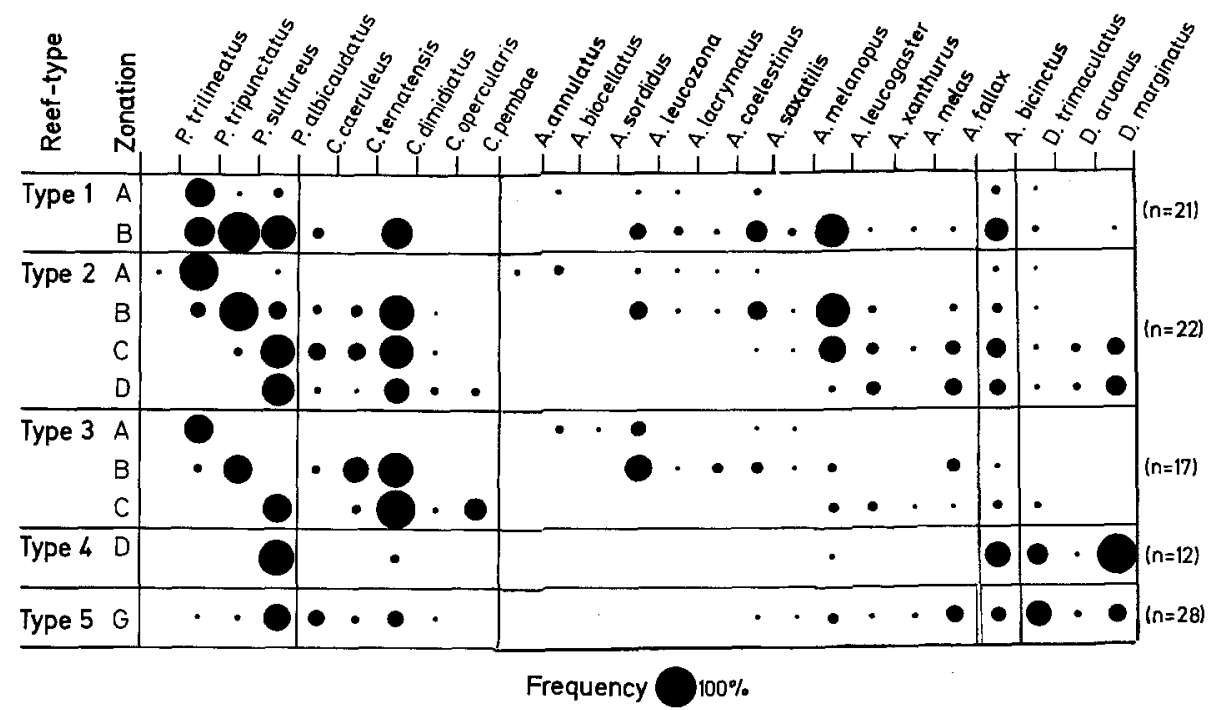

Fig. 2: Frequency of the species in different reef zones and reef types ( $\mathrm{n}$ : number of transects)

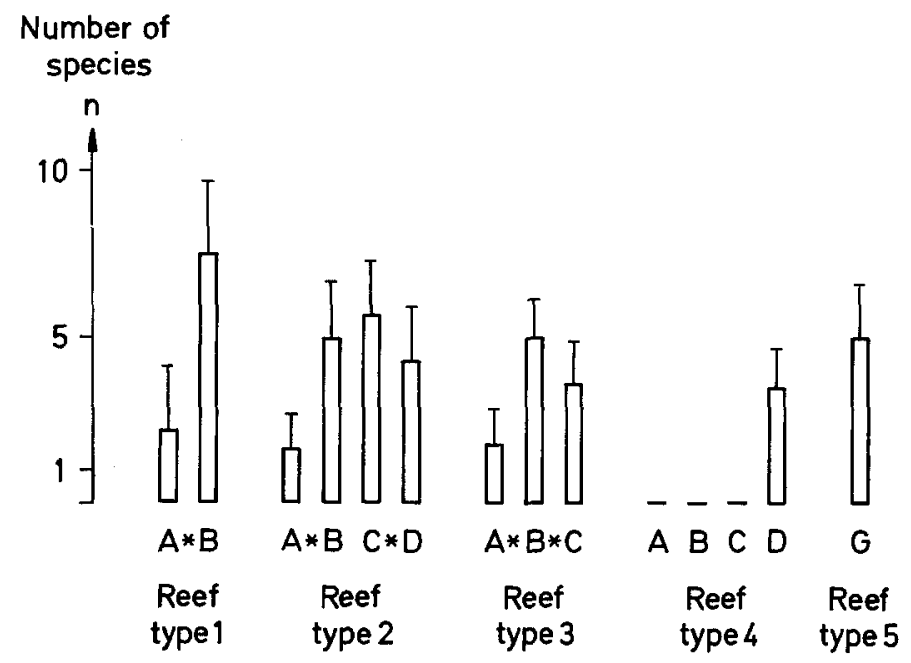

Fig. 3: Total transect average of species numbers in different zones and reef types. Asterix between two bars indicates statistical significance of $p<0.01$ (t-test)

Zones B, C) and in Halophila weeds on soft bottoms (reef type 4, Zone A). These findings correspond with obervations by Emery (1973) on Caribbean species and by Gosline (1965) on Hawaian species. Several species are typical shallow-water dwellers: Pomacentrus trilineatus, $P$. tripunctatus, Abudefduf annulatus and A. biocellatus. Others are "universalists", occurring in nearly all zones: $P$. albicaudatus, almost all Chromis species, Dascyllus trimaculatus and A. leucogaster. It is surprising that the 
symbiotic anemone fish Amphiprion bicinctus is one of the most widely distributed fishes.

Figure 3 shows the number of species in each zone. We can see that species diversity increases with coral abundance. Zone B with the reef edge supports most pomacentrids; a large variety is found on coral knolls.

\begin{tabular}{llllllllllll}
$\begin{array}{l}\text { Ree } \\
\text { type }\end{array}$ & Zone & \multicolumn{10}{c}{ Rank of relative abundance } \\
& & 1 & 2 & 3 & 4 & 5 & 6 & 7 & 8 & 9 & 10 \\
\hline Type 1 & A & 2 & 22 & & & & & & & & \\
Type 2 & A & 2 & & & & & & & & & \\
Type 3 & A & 2 & 13 & & & & & & & & \\
\hline Type 1 & B & 3 & 4 & 7 & 18 & 2 & 16 & 22 & 5 & 17 & 13 \\
Type 2 & B & 7 & 3 & 18 & 16 & 4 & 6 & 2 & 13 & 5 & 22 \\
Type 3 & B & 7 & 6 & 13 & 3 & 21 & 5 & 16 & 15 & & \\
\hline Type 2 & C & 7 & 4 & 5 & 21 & 18 & 6 & 25 & 22 & 19 & \\
Type 3 & C & 7 & 9 & 4 & 6 & 19 & 18 & & & & \\
\hline D. \\
\hline Type 2 & D & 4 & 7 & 21 & 25 & 19 & 22 & 5 & & & \\
Type 4 & D & 25 & 4 & 23 & 22 & & & & & & \\
\hline Type 5 & G & 21 & 4 & 5 & 23 & 7 & 25 & 22 & 18 & & \\
\hline
\end{tabular}

Fig. 4: Rank list of the most abundant species in different reef types and zones

To ascertain which of these species coexist most commonly, we omitted those below $20 \%$ frequency in any zone, and ranked the remaining species according to their relative abundance index, calculated from the frequency and relative density data. Figure 4 lists the species in order of decreasing abundance, so that for each zone we can recognize typical communities:

Zone A: Pomacentrus tripunctatus, Abudefduf leucozona, Ampbiprion bicinctus

Zone B: Chromis dimidiatus, Pomacentrus sulfureus, C. ternatensis, P. albicaudatus

Zone C: Chromis dimidiatus, Pomacentrus albicaudatus, C. ternatensis, Abudefduf leucogaster, $A$. xanthurus

Zone D: Dascyllus marginatus, $P$. albicaudatus, D. trimaculatus, A. bicinctus.

Coral knolls also have their own pomacentrid community: A. fallax, P. albicaudatus,

$C$. caeruleus, D. trimaculatus, C. dimidiatus, D. marginatus, A. bicinctus, A. leucogaster.

This is a semi-quantitative description of the pomacentrid communities in reef zones and reef types chosen at random. I admit that much information is lost in this marshalling of data, but at least we get a picture of the coexisting species. Our next question is, how is this coexistence possible? What particular ecological conditions allow the species to live together with minimum competition? 


\section{ECOLOGICAL REQUIREMENTS OF EXAMINED SPECIES}

The following ecological parameters were investigated: type of habitat, feeding type, and home- and shelter-site selection.

(1) Type of habitat: The fishes are diurnal, remaining by day either near the bottom or foraging in the water column above their home range. Bottom-living species were defined as those remaining within $50 \mathrm{~cm}$ of the substrate; midwater species ascend higher.

(2) Feeding type: Stomach analysis of all species showed the pomacentrids of the Gulf of Aqaba to be herbivorous, omnivorous or plankton-carnivorous.

(3) Home-and-shelter-site selection: The substrate of the home-and-shelter-site was determined. This is occupied by night, and during resting periods by day, it is also used to excape from predator attacks or in response to other alarm stimuli. The selection of substrate was classified as either specialized or unspecialized. Specialization exists when a species exhibits habitat preference. Chromis caeruleus, D. aruanus and $D$. marginatus are coral-dwelling species; Amphiprion species inhabit sea anemones. All other species are able to live on various substrates, that is, they are unspecialized,

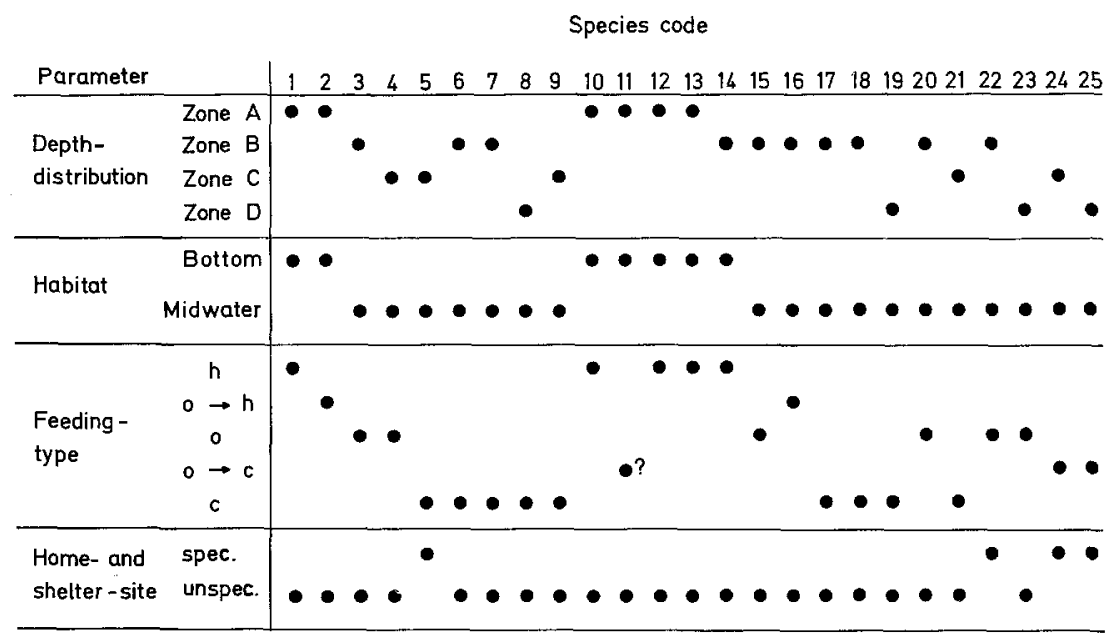

Fig. 5: Species studied (cf. Table 1) and their ecological requirements

Figure 5 includes both ecological parameters and the main depth distribution of the species, independent of reef type. Most bottom-dwelling species occur in shallow waters, and are mainly herbivorous. Midwater species are mostly omnivorous or plankton-carnivorous. One species is puzzling. A. biocellatus is described as herbivorous (Hiatt \& Strasburg, 1960), but we found parasitic copepods in its stomach. The plankton feeders sometimes form huge anonymous stationary schools. Obviously, the occurrence of plankton could be a limiting factor for their distribution. Figure 5 shows that plankton feeders occur throughout the reef, at all depths, thus achieving a more thorough exploitation of resources. 
The pomacentrids are specialized and adapted in depth distribution, habitat selection, feeding, and selection of the home-and-shelter-site, all of which combine to permit a sharing of the available resources with minimal interspecific competition. I admit that a much more specific ecological specialization of the species may exist; this however, is not detectable with the methods used.

\section{INTERSPECIFIC COMPARISON OF SOCIAL SYSTEMS AND ECOLOGY OF THE SPECIES}

The social organization of a species is thought to be adapted to the average conditions prevailing in the area populated. Group life, therefore, is one of the main adaptive features ensuring individual population survival. Which social structures are established in different ecological niches? Are these structures correlated with ecological parameters? A group is defined as a set of organisms of the same species that remain together and interact with one another to a distinctly greater degree than with other conspecifics (Wilson, 1975).
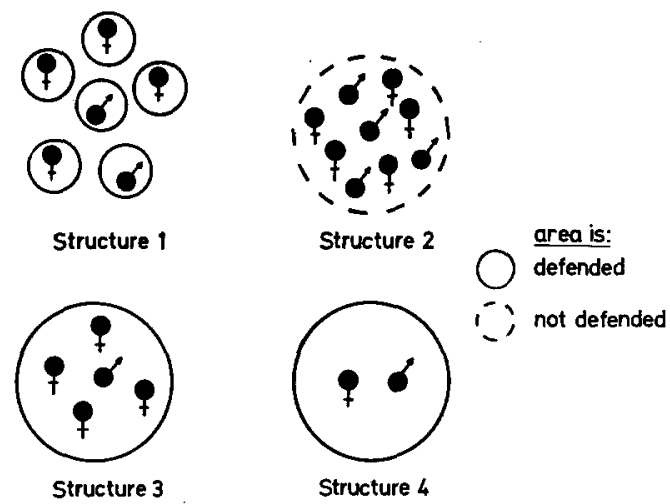

Fig. 6: Variation in social structure between different species. In Structures 1, 2 and 3, group size can vary according to environmental limits. The sex sign indicates mature, sexually active individuals

Four social structures were distinguished in long-term observations over 56 months, by tagging group members, histological examinations of the sexes and detailed behaviour studies of single groups of several species (Fricke 1973, 1974, 1975a, 1975b, 1975c; Fricke \& Holzberg 1974). These social structures are defined as follows (Fig. 6): Structure 1: stationary permanent group of territorial solitary males and females Structure 2: stationary permanent group of many males with many females Structure 3: stationary permanent group of 1 male with several females (polygynous or harem structure)

Structure 4: stationary permanent group of 1 male with 1 female (monogamous structure).

Several species are capable of altering their social structure if the environmental influences change. For our present study, however, the most frequently observed social 


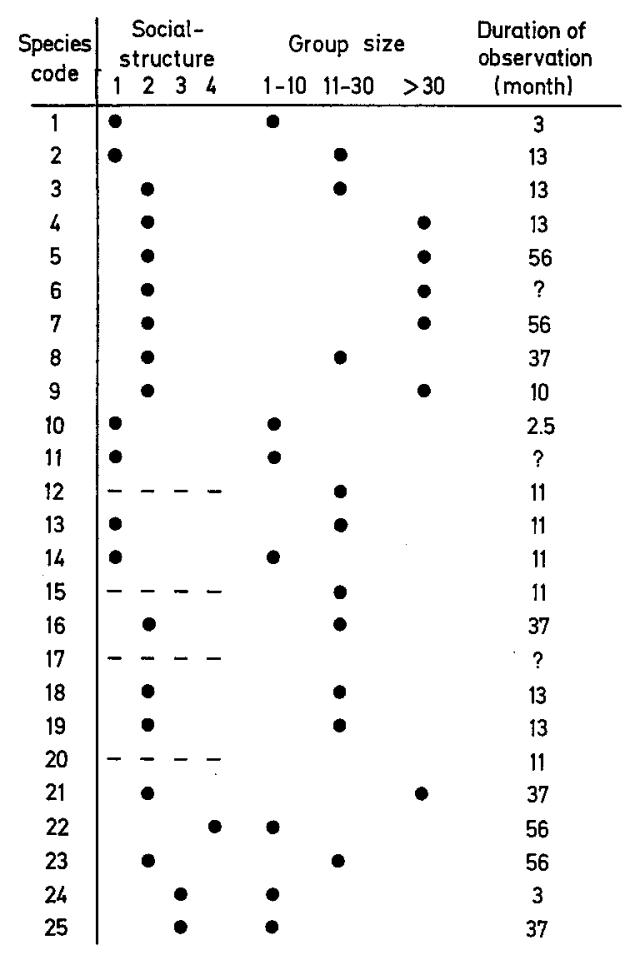

Fig. 7: Social structure, average group size and duration of observation

\begin{tabular}{|c|c|c|c|c|c|}
\hline \multirow{2}{*}{ Parameter } & & \multicolumn{4}{|c|}{ Social structure } \\
\hline & & Struct.1 & Struct.2 & Struct.3 & Struct.4 \\
\hline \multirow{4}{*}{$\begin{array}{l}\text { Depth - } \\
\text { distribution }\end{array}$} & Zone $\mathrm{A}$ & 5 & - & - & - \\
\hline & Zone $\mathrm{B}$ & 1 & 5 & - & 1 \\
\hline & Zone $\mathrm{C}$ & - & 4 & 1 & - \\
\hline & Zone $\mathrm{D}$ & - & 3 & 1 & - \\
\hline \multirow{2}{*}{ Habitat } & Bottom & 6 & - & - & - \\
\hline & Midwater & - & 12 & 2 & 1 \\
\hline \multirow{5}{*}{$\begin{array}{l}\text { Feeding - } \\
\text { type }\end{array}$} & $\mathrm{h}$ & 4 & - & - & - \\
\hline & $a \rightarrow h$ & 1 & 1 & - & - \\
\hline & 0 & - & 2 & - & 1 \\
\hline & $0 \rightarrow c$ & (1)? & 1 & - & - \\
\hline & c & - & 8 & 2 & - \\
\hline \multirow{2}{*}{$\begin{array}{l}\text { Home- and } \\
\text { shelter-site }\end{array}$} & spec. & - & 1 & 2 & 1 \\
\hline & unspec. & 6 & 11 & - & - \\
\hline $\begin{array}{l}\text { Total number } \\
\text { of species }\end{array}$ & & 6 & 12 & 2 & 1 \\
\hline
\end{tabular}

Fig. 8: Relationships between social structures and ecological parameters 
structure is taken as species-specific. Group size and social structure of 21 of the 25 species could be determined. The Figure 7 indicates that social systems have evolved independently of pomacentrid taxonomic relationships. Now let us consider the social structures in the light of ecological factors.

Figure 8 provides data on social structure, distribution and the ecological requirement of each species. For example, social Structure 1 obtains in six species, five living in Zone A and only one in Zone B. All species are bottom-living, most are herbivorous or omnivorous with herbivorous tendency. All six species are unspecialized in their selection of the home-and-shelter-site.

We also find that Structure 2 species are most frequent in midwater of all zones. The plankton-carnivores occur in this type. Social structures 3 and 4 are rare, occurring in species specialzing in home-and-shelter-site. These are Ampbiprion bicinctus, Dascyllus aruanus and D. marginatus.

To determine the significance of the relationship between social structure and ecological parameters, we used a common biometric method (see Spielmann et al., 1974). Each parameter formes an axis of a polydimensional system of coordinates, each species being described by its species-specific coordinates. Details of this method are given in an earlier paper (Fricke, 1975a). Proximity of any two species can be defined as a measure of their ecological similarity; disparity in ecological requirements is reflected by greater distance. The distance $d$ can easily be calculated by extending the Pythagorean theorem. If Species $A$ is described by its coordinates $x_{1}, y_{1}$ and $z_{1}$, and Species $\mathrm{B}$ by its coordinates $\mathrm{x}_{2}, \mathrm{y}_{2}$ and $\mathrm{z}_{2}$, then the distance between them is:

$$
\mathrm{d}=\sqrt{\left(x_{1}-x_{2}\right)^{2}+\left(y_{1}-y_{2}\right)^{2}+\left(z_{1}-z_{2}\right)^{2}}
$$

\section{Species code}

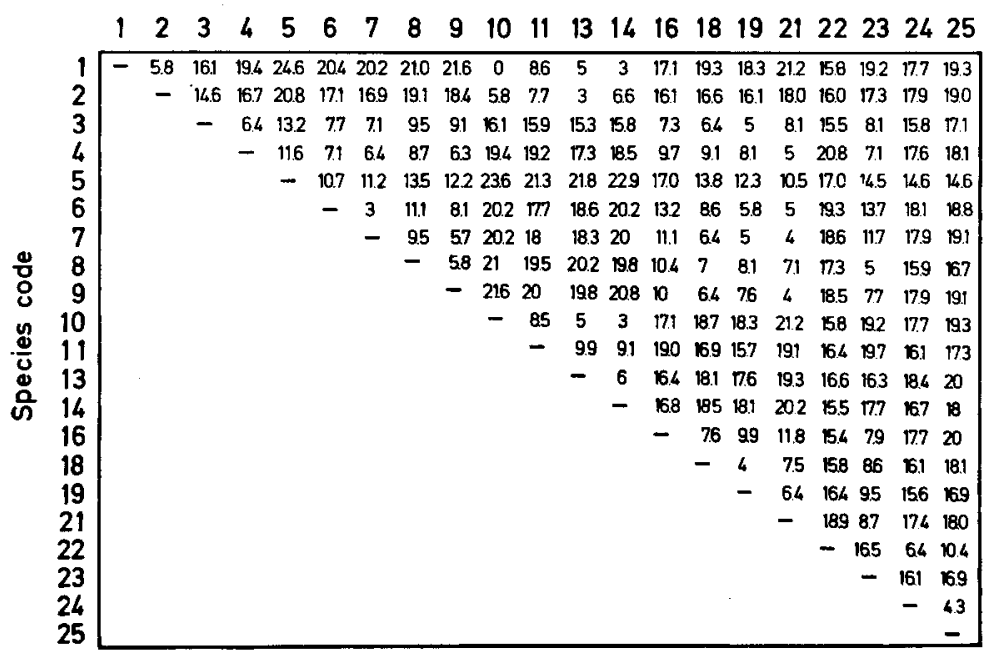

Fig. 9: Matrix of generalized distances between species in a polydimensional system of coordinates. The axes of the system are standardized; scale of values: $0-10$. (For calculation of distance values see text) 
Figure 9 gives a matrix with the generalized distances between all observed pomacentrid species. In a further step of the analysis, species having the same social structure were selected and the distances from each other calculated; then the distances to species with other social structures were determined. If our hypothesis were correct species having the same social structure are similarly specialized ecologically - then the mean distance from each other should be significantly less than their mean distance to species of another social structure.

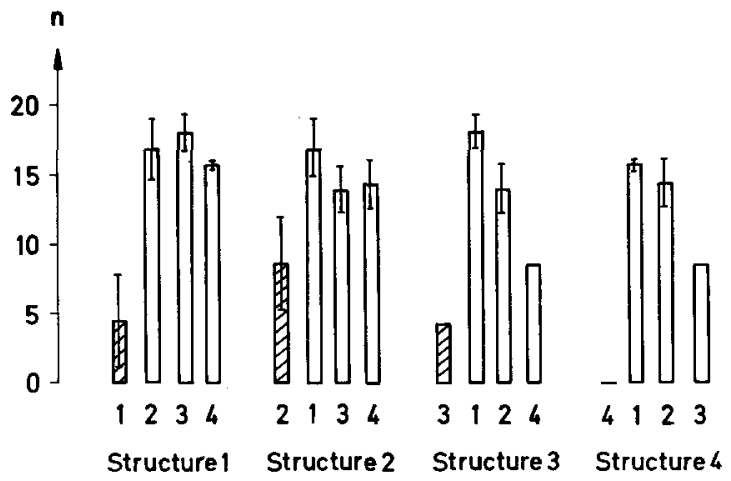

Fig. 10: Relationship between ecological parameters and social structure. $\mathrm{n}$ : generalized distance in a polydimensional system of coordinates (see text and Table 6). Hatched bars: mean distance and standard deviation of all species of one particular social type, white bars: mean distance and standard deviation of species of one social type to all species of other social types

This mean proximity was actually found in species of one social structure (Fig. 10). The differences to species of other social structure are statistically highly significant $(p<0.001 ; t$-test). We can suppose that each social structure evolved under particular ecological conditions. But the data should be interpreted with care, because they say nothing about causal relationships. The latter cannot be explored with simple tables of correlations, so we have to leave the level of interspecific comparison and examine the direct influence of environmental factors on the behaviour and social structures of groups of on e species. That is, we are seeking the range of behaviour modification within the limits of the present genetic potential of the species.

\section{INTRASPECIFIC DIFFERENCES IN BEHAVIOUR AND SOCIAL STRUCTURE IN RESPONSE TO LOCAL VARIATIONS OF THE ENVIRONMENT}

This important topic of pomacentrid behaviour and ecology is very inadequately investigated. Consequently, there are gaps in my presentation. We are only just beginning to understand that pomacentrids are extremely flexible in their behavioural responses to immediate environmental influences. 
Many authors have reported changes in home-range size under the immediate influence of fluctuations in water movement or visibility, or group-size increase (Myrberg et al., 1967; Fishelson, 1970; Stevenson, 1972; Emery, 1973; Fricke, 1974, 1975a). In general, feeding areas are larger in calm, clear waters. The same group occupies a smaller area if the water is turbulent or dirty. Plankton feeders ascend higher in the water column if their group size increases, probably due to schooling as an antipredation mechanism.

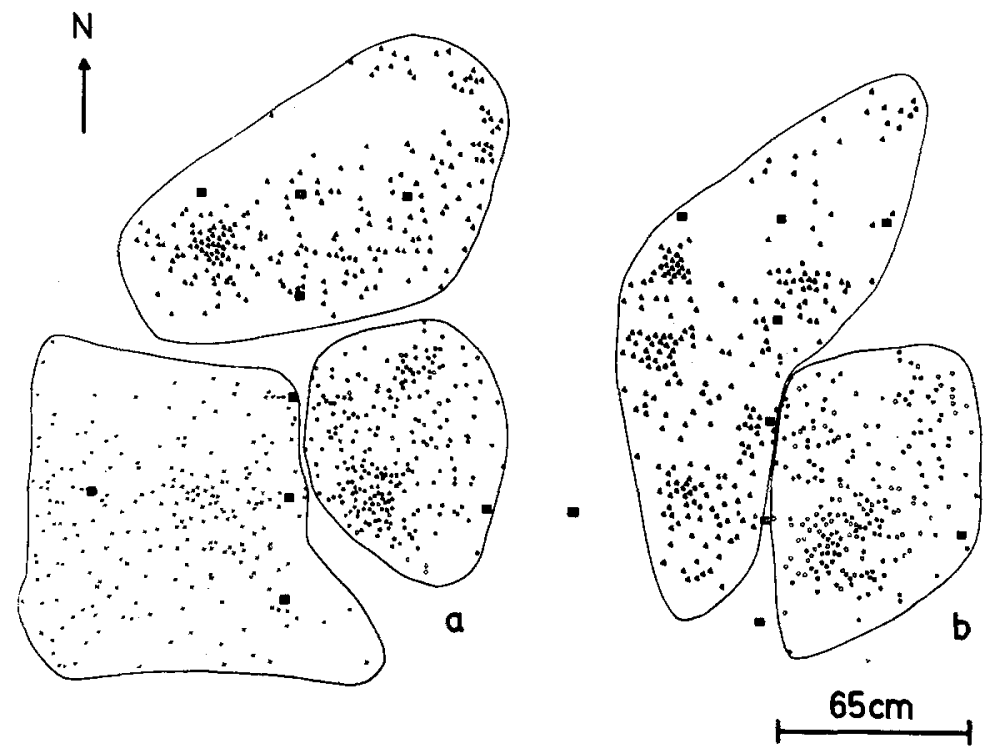

Fig. 11: Territory size of 3 neighbouring groups of Dascyllus aruanus. After removal of the dominant group (dominant in territorial aggression) the next-ranking group took over the territory. Black squares represent artifical landmarks for better identification of territories. Positions of group members were recorded every $30 \mathrm{sec}$ over a period of $15 \mathrm{~min}$ at 09:00, $13: 00$ and $17: 00$

The size of the home range also varies because of inter-group pressure. Figure 11 illustrates the home range of three groups of Dascyllus aruanus. The biggest area is occupied by the dominant group. After removal of the dominant group, the nextlower-ranking group takes over. Home-range size is also influenced by predators, even by sex and body size. We measured home ranges of pairs of Amphiprion bicinctus. In areas with relatively few predators, the total water volume occupied was $30 \mathrm{~m}^{3}$ for the larger female, and $8 \mathrm{~m}^{3}$ for the smaller male (Fricke, 1974), but in reef areas under strong predation it was only a few cubic metres. Amphiprion species are normally plankton feeders using a large water column. When I forced some plankton-feeding individuals into about $1 \%$ of their former area, their feeding habits changed and they all became herbivores, but suffered no weight loss over a period of three month.

Pomacentrids are opportunistic feeders, capable of varying their feeding strategy. In deeper waters or in areas with constant currents, Dascyllus aruanus is a true plankton carnivore; however, it becomes omnivorous or even herbivorous in shallow, calm 
lagoons. Choates (pers. comm.) discovered a feeding net; he observed that smaller $D$. aruanus feed lower in the water column, bigger individuals higher up. This is probably true for many plankton feeders of the reef.

This list of rapid behavioural responses to the immediate influences of changing environmental parameters could easily be lengthened. That changes also occur due to seasonal, longterm modification of the environment was recently demonstrated in Myberg \& Tresher's (1973) fine study on territorial aggression in pomacentrids.

However, it is not only certain biotope-oriented behavioural patterns which change in response to local environmental variations. Group structures, too, are altered. We still do not fully appreciate what tremendous changes of group structure occur. The species Pomacentrus albicaudatus, for example, normally lives in big stationary groups of many males and females (Fig. 4, Structure 2). In areas deficient in plankton,

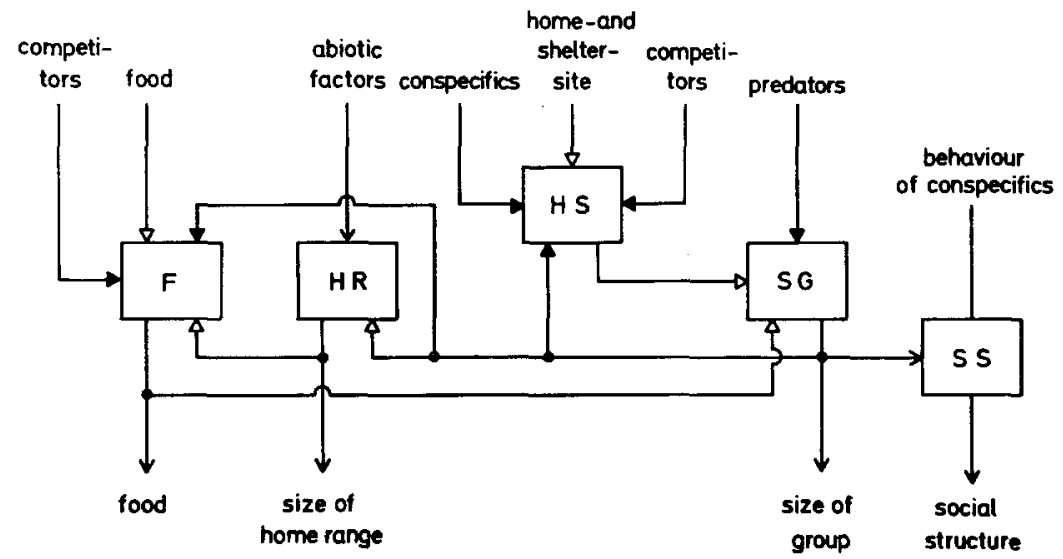

Fig. 12: Hypothetical flow diagram of the influence of input variables (food, numbers of conspecifics, home- and shelter-sites, predators, competitors for food and home-and-shelter-sites) on the output variables (food, home range size, group size, social structure). Squares: black boxes or systems with unknown characteristics. Letters in squares: references to black boxes or systems. Arrows: variables and direction of causal dependence. Arrows pointing to squares: input variables, pointing away from squares: output variables. Triangular black (white arrowhead: diminishing (increasing) influence on subsequent variable; isolated arrow: uninvestigated input variable

however, harem structures are formed, or even a territorial, solitary mode of life is adopted. Feeding habits are changed, and a territory is defended if resources are limited. The same holds for Dascyllus trimaculatus, which generally forms big groups (Fricke, 1973) of Structure 2. The do not defend their home range. If suitable homeand-shelter-sites are limited, however, the number of males is drastically reduced and polygyny results (Structure 3). Reduction of males also occurs in several normally solitary species. I will later return to the functional aspect of this male reduction.

To summarize: fast-changing environmental influences induce immediate behavioural changes. Food, abiotic factors (light, temperature, water turbidity), the home-and-shelter-site, predator influence, and food and shelter competitors are some of the factors which immediately influence individual and group behaviour. Figure 12 
shows a hypothetical flow diagram of the influence of these factors on some measurable outputs, considered at the group level: the food still available, home range size, group size, and social structure. This diagram is merely an incomplete working hypothesis showing the way to further investigations. Here follows an example of the type of experiment still to be conducted.

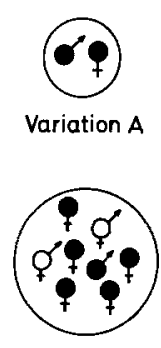

Variation C
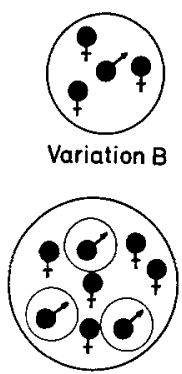

Variation D

Fig. 13: Dascyllus arnanus. Variation of social structure. Black sex signs: mature, sexually active individuals; white sex signs: mature, but sexually suppressed individuals

The flow diagram indicates that home-and-shelter-sites should have a paramount influence on group size and social structure. The number and quality of the sites available could determine the group structure. I concentrated on species for which these sites were probably a limiting factor. Earlier, I mentioned that four species were specialized in their selection of home-and-shelter-sites: the coral-dwellers Chromis caeruleus, Dascyllus aruanus, D. marginatus and the symbiotic anemone fish Amphiprion.

Dascyllus aruanus occurs in nature in groups with for different variations in social structure (Fig. 13). At one time, Variation B was considered synonymous with Structure 2 (Fig. 6), because it is most frequently observed. $D$. aruanus is a protogynous hermaphrodite (Reinboth \& Fricke, in prep.) and displays aggressive rank order (Sale, 1972; Fricke \& Holzberg, 1974). By their aggressive dominance over the females, males probably control the procreation of other males. We can assume that group size is controlled by coral size, that is, by the number and quality of suitable home-and-shelter-sites, as well as by a sufficient water volume for feeding. The system should react at once if the home-and-shelter-site, as one important environmental factor, is altered experimentally. Theoretically, smaller corals should harbour groups with fewer males and more females, because egg number determines reproductive success, and one thale can fertilize and guard the eggs of several females. Additional males should be a "luxury" for the group, and are probably counter-selected. I proved this hypothesis in the following field experiment. Artificial populations, each consisting of 3 males and 3 females, were placed on two types of coral, one being a single coral head, the other a big coral with up to 10 heads of Stylophora pistillata. I observed the progressive rate of survival of the sexes day by day. Figure 14 gives the mean number of surving males and females of 11 groups in small corals and of 6 groups in large corals. The 
results suggest a strong selection against males, that is, an immediate adaptation occured in the reproductive strategy. Recent, more detailed experiments with Dascyllus marginatus revealed identical results (Fricke \& Fricke, in prep.).
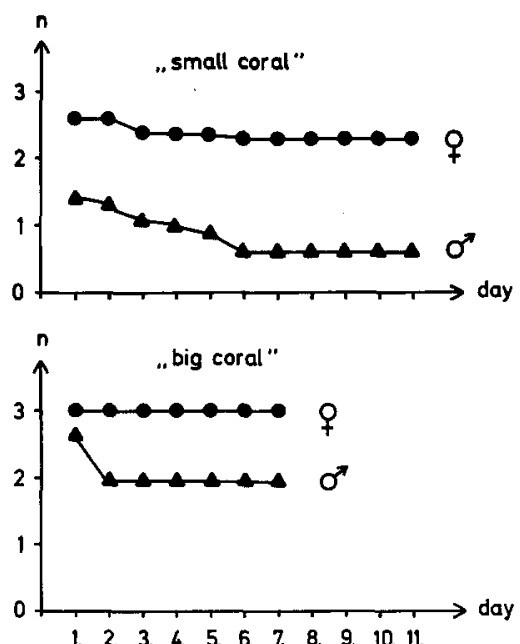

Fig. 14: Decreasing survival of males and females in two experimental situations on different days. The experiment was terminated if the mean number of males and females remained constant over at least 6 days. Each experiment commenced with 3 males and 3 females

In the future, we shall continue with this kind of experimentation, altering and monitoring environmental factors and analyzing behavioural responses of groups and inidviduals. We work with small groups isolated in a huge wire-netting cage in the coral reef. Predator numbers and competitors for food and shelter sites are controlled. To a certain extent, we are also able to regulate the flow of plankton in the cage. Our aim is to investigate in this closed, semi-natural ecosystem, the behavioural strategies of individuals and groups. We hope this may lead to a system allowing predictions of environmental influences on behaviour. The pilot study has been done. We are now ready for the next step.

\section{LITERATURE CITED}

Emery, A. R., 1973. Comparative ecology and functional osteology of fourteen species of damselfish (Pomacentridae) at Alligator Reef, Florida Keys. Bull. mar. Sci. 23, 649-770.

Fishelson, L., 1970. Behaviour and ecology of a population of Abudefuf saxatilis (Pomacentridae). Anim. Behav. 18, 225-237.

- Popper, D. \& Avidor, A., 1974. Biosociology and ecology of pomacentrid fishes around the Sinai Peninsula (Northern Red Sea). J. Fish Biol. 6, 119-133.

Fricke, H. W., 1973. OKologie und Sozialverhalten des Korallenbarsches Dascyllus trimaculatus. Z. Tierpsychol. 32, 225-256.

- 1974. Oko-Ethologie des monogamen Anemonenfisches Ampbiprion bicinctus. Z. Tierpsychol. 36, 429-512. 
- 1975a. Sozialstruktur und ökologische Spezialisierung von verwandten Fischen (Pomacentridae). Z. Tierpsychol. 39, 492-520.

- 1975b. Selektives Feinderkennen beim Anemonenfisch Ampbiprion bicinctus. J. exp. mar. Ecol. Biol. 19, 1-7.

- 1975c. Evolution of social systems through site attachment in fish. Z. Tierpsychol. 39, 206-210.

- \& Holzberg, S., 1974. Social units and hermaphroditism in a pomacentrid fish. Naturwissenschaften 61, 367-368.

Gosline, W. A., 1965. Vertical zonation of inshore fishes in the upper water layer of the Hawaiian Islands. Ecology 46, 823-831.

Hiatt, R. W. \& Strasburg, D. W., 1960. Ecological relationships of the fish fauna on coral reefs of the Marshall Islands. Ecol. Monogr. 30, 65-127.

Mergner, H. \& Schuhmacher, H., 1974. Morphologie, Okologie und Zonierung von Korallenriffen bei Aqaba (Golf von Aqaba, Rotes Meer). Helgoländer wiss. Meeresunters. 26, $238-358$.

Myrberg, A. A., 1972a. Ethology of the bicolor damselfish Eupomacentrus partitus (Pisces, Pomacentridae): A comparative analysis of laboratory and field behaviour. Anim. Behav. Monogr. 5, 197-283.

- 1972b. Social dominance and territoriality in the bicolor damselfish, Eupomacentrus partitus (Pisces, Pomacentridae). Behaviour 41, 207-231.

- \& Thresher, R. E., 1974. Interspecific aggression and its relevance to the concept of territoriality in reef fish. Am. Zool. 14, 81-96.

- Brahy, B. D. \& Emery, A. R., 1967. Field observation on the reproduction of the damselfish Chromis multileneata (Pomacentridae), with additional notes on general behavior. Copeia 4, 818-827.

Sale, P., 1972. Effect of cover on agonistic behaviour of a reef fish. Ecology 53, 753-758.

Spielman, R. S., Migliazza, E. C. \& Neel, J. V., 1974. Regional linguistic and genetic differences among Yanomama Indians. Science, N.Y. 184, 637-644.

Stevenson, R. A., 1972. Regulation of feeding behavior of the bicolor damselfish Eupomacentrus partitus by environmental factors. In: Behaviour of marine animals. Ed. by $\mathrm{H}$. E. Winn \& B. L. Olla. Plenum Press, New York, 2, 278-302.

Wilson, E. O., 1975. Sociobiology. The Belknap Press of Harvard University Press, Cambridge, $697 \mathrm{pp}$.

Author's address: Dr. H. W. Fricke

Max-Planck-Institut für Verhaltensphysiologie

D-8131 Seewiesen

Federal Republic of Germany 